OPEN ACCESS

Edited by:

Hongbo Liu,

University of Pennsylvania,

United States

Reviewed by:

Alexander Vaiserman,

Institute of Gerontology (NAN

Ukraine), Ukraine

George A. Garinis,

Foundation for Research

and Technology Hellas, Greece

*Correspondence:

Qing-Peng Kong

kongqp@mail.kiz.ac.cn

Specialty section:

This article was submitted to

Genetics of Aging,

a section of the journal

Frontiers in Genetics

Received: 09 December 2018

Accepted: 30 January 2019

Published: 18 February 2019

Citation:

Xiao $\mathrm{F}-\mathrm{H}$, Wang $\mathrm{H}-\mathrm{T}$ and Kong Q-P (2019) Dynamic DNA Methylation During Aging: A "Prophet"

of Age-Related Outcomes.

Front. Genet. 10:107.

doi: 10.3389/fgene.2019.00107

\section{Dynamic DNA Methylation During Aging: A "Prophet" of Age-Related Outcomes}

\author{
Fu-Hui Xiao ${ }^{1,2,3,4,5}$, Hao-Tian Wang ${ }^{1,2,3,4,5,6}$ and Qing-Peng Kong 1,2,3,4,5* \\ ' State Key Laboratory of Genetic Resources and Evolution, Kunming Institute of Zoology, Chinese Academy of Sciences, \\ Kunming, China, ${ }^{2}$ Center for Excellence in Animal Evolution and Genetics, Chinese Academy of Sciences, Kunming, China, \\ ${ }^{3}$ Key Laboratory of Healthy Aging Research of Yunnan Province, Kunming, China, ${ }^{4}$ Kunming Key Laboratory of Healthy \\ Aging Study, Kunming, China, ${ }^{5} \mathrm{KIZ/CUHK}$ Joint Laboratory of Bioresources and Molecular Research in Common Diseases, \\ Kunming, China, ${ }^{6}$ Kunming College of Life Science, University of Chinese Academy of Sciences, Beijing, China
}

The biological markers of aging used to predict physical health status in older people are of great interest. Telomere shortening, which occurs during the process of cell replication, was initially considered a promising biomarker for the prediction of age and age-related outcomes (e.g., diseases, longevity). However, the high instability in detection and low correlation with age-related outcomes limit the extension of telomere length to the field of prediction. Currently, a growing number of studies have shown that dynamic DNA methylation throughout human lifetime exhibits strong correlation with age and age-related outcomes. Indeed, many researchers have built age prediction models with high accuracy based on age-dependent methylation changes in certain CpG loci. For now, DNA methylation based on epigenetic clocks, namely epigenetic or DNA methylation age, serves as a new standard to track chronological age and predict biological age. Measures of age acceleration ( $\triangle$ age, DNA methylation age - chronological age) have been developed to assess the health status of a person. In addition, there is evidence that an accelerated epigenetic age exists in patients with certain age-related diseases (e.g., Alzheimer's disease, cardiovascular disease). In this review, we provide an overview of the dynamic signatures of DNA methylation during aging and emphasize its practical utility in the prediction of various age-related outcomes.

Keywords: DNA methylation, epigenetic clock, age, age-related outcome, prediction

\section{INTRODUCTION}

Aging is an inevitable biological process accompanied by progressive decline in physical function and increased risk of multiple age-related diseases, such as cardiovascular disease, neurodegenerative disease, and cancer (Sen et al., 2016). Currently, human populations across the world are rapidly aging (Lutz et al., 2008; Christensen et al., 2009). Age-related chronic diseases 
account for most global diseases as well as morbidity and mortality (Kennedy et al., 2014). For example, cardiovascular disease, one of the most common diseases of aging, accounted for $30 \%$ of all deaths worldwide per year (Pagidipati and Gaziano, 2013; Nichols et al., 2014). Consequently, the development of tools to diagnose and predict age-dependent risks has enormous significance in preventing age-related diseases and improving the health status of the elderly.

The process of aging results in multiple changes at both the molecular and cellular level, including cellular senescence, telomere attrition, and epigenetic alterations (Lopezotin et al., 2013). Among these hallmarks, telomere length, which experiences progressive shortening during replication of somatic cells, is a remarkable characteristic of aging and linked with age-related health status (Rizvi et al., 2015). However, recent evidence has revealed that the correlation between telomere length and age-related outcomes of individuals is low (Müezzinler et al., 2013; Breitling et al., 2016; Marioni et al., 2016). Thus, investigators are still searching for other biomarkers that can be used in the prediction of age-related outcomes with higher accuracy.

Current studies have indicated that epigenetic changes comprise a significant component of the aging process (Jones et al., 2015). Epigenetics refer to the modulation of gene activity without any change in the genomic sequence. Wellstudied epigenetic modifications include DNA methylation, histone modification, and non-coding RNA, with changes in dynamic DNA methylation found to be most associated with the aging process (Richardson, 2003b; Fraga and Esteller, 2007; Sen et al., 2016). In general, age-dependent changes in DNA methylation include global hypomethylation and region-specific hypermethylation (Xiao et al., 2016). Abundant studies have demonstrated a close relationship between DNA methylation and aging and longevity (Feinberg et al., 2002; Robertson, 2005; Xiao et al., 2016). These findings have impelled researchers to develop age predictors based on the correlation between methylation changes and chronological age (Hannum et al., 2013; Horvath, 2013). DNA methylation age, evaluated by these predictors, reflects the biological age of a person, which has a close association with individuals' health status and can be changed by multiple risk factors, such as smoking and obesity (Dugué et al., 2018). Therefore, the difference between DNA methylation age and chronological age (i.e., $\Delta$ age) may be a promising tool in predicting disease risk and longevity potential in early life (Vaiserman, 2018). Here, we review the dynamics of methylation in aging and discuss the roles of age-dependent methylation changes in the prediction of age and age-related outcomes.

\section{DNA METHYLATION}

DNA methylation, a well-studied epigenetic modification, refers to the transfer of a methyl $(\mathrm{CH} 3)$ group from $S$-adenosyl methionine (SAM) to the fifth position of cytosine nucleotides, forming 5-methylcytosine (5mC) (Hotchkiss, 1948; Chiang et al., 1996; Moore et al., 2013). This process is catalyzed by at least three DNA methyltransferases, including Dnmt1, Dnmt3a, and
Dnmt3b (Okano et al., 1999; Vilkaitis et al., 2005). Among these enzymes, Dnmt1 is responsible for the maintenance of methylation patterns in the genome by replicating the hemimethylated CpG sites (Vilkaitis et al., 2005), whereas Dnmt3a/b are considered de novo methyltransferases (Okano et al., 1999). Otherwise, evidence has shown that DNA demethylation can be achieved by either passive or active mechanism (Chen and Riggs, 2011). The passive demethylation can be caused by the inhibition of Dnmt1 during cell replication (Wolffe et al., 1999); while the active demethylation is modulated by the DNA demethylases. In the past, $5 \mathrm{mC}$ DNA glycosylase (5-MCDG) and methyl-CpG binding domain protein 4 (MBD4) have been served with the activity of DNA demethylase (Jost et al., 1999; Hendrich et al., 1999; Zhu, 2009). Recent years, amounting evidence has shown ten-eleven translocation (TET) dioxygenases play important roles in DNA demethylation through converting 5-methylcytosine to 5-hydroxymethylcytosine (Jin et al., 2014; Ichiyama et al., 2015).

In mammalian cells, most $5 \mathrm{mC}$ occurs at nucleic sequences in the context of cytosine-phosphate-guanine $(\mathrm{CpG})$ dinucleotides. About $70-80 \%$ of $\mathrm{CpG}$ sites are methylated in human somatic cells, with most unmethylated $\mathrm{CpG}$ sites clustered in the $\mathrm{CpG}$ island located on the promoter region of the genes (Ehrlich et al., 1982; Lister et al., 2009). Accumulated evidence has shown that DNA methylation plays essential roles in many biological processes, including gene regulation, chromosome stability, genomic imprinting, and $\mathrm{X}$ chromosome inactivation (Robertson, 2005). Many studies have revealed that mammalian developmental processes cannot depart from modulation of DNA methylation (Trowbridge et al., 2009). One remarkable case comes from stem-cell differentiation. All myeloid and lymphoid blood lineages are differentiated from hematopoietic stem cells (HSCs) (Chao et al., 2008), during which the activity of genes (e.g., KCNH2, SUSD3) that control cell fate is highly regulated by methylation status (Farlik et al., 2016). Conversely, abnormal DNA methylation is related to the occurrence of several human diseases (Feinberg et al., 2002; Robertson, 2005), with many studies showing the role of aberrant DNA methylation in the activation of tumor promoter genes (e.g., MAGE, S100P) and silencing of tumor suppressor genes (e.g., VHL, MLH1) in various cancers (Herman and Baylin, 2003; Sato et al., 2004). Additionally, there are researches that abnormal methylation plays an important role in the pathogenesis of autoimmune diseases (e.g., idiopathic human lupus), metabolic syndromes (e.g., hyperglycemia), and neurological disorders (e.g., autism spectrum disorder) (Richardson, 2003a; Côté et al., 2016; Andrews et al., 2018).

Generally, DNA methylation in regions near the transcription start site (TSS) is closely associated the suppression of gene expression (Bird, 1986; Eden and Cedar, 1994). Accumulating evidence has shown that transcriptional suppression of DNA methylation involves prevention of transcription activation factor (e.g., AP-2) or recruitment of transcription inhibiting factor (e.g., MeCP2) binding to TSS regions (Comb and Goodman, 1990; Jones et al., 1998; Fuks et al., 2003). On the contrary, there are reports that gene body methylation likely increases transcriptional activity (Maunakea et al., 2010; Yang et al., 2014). 
Emerging evidence has shown that DNA methylation on gene body functions can protect the gene body from spurious transcripts by guaranteeing the fidelity of mRNA transcription initiation (Neri et al., 2017).

\section{ASSOCIATION BETWEEN DYNAMIC DNA METHYLATION AND AGING/AGE-RELATED DISEASES}

The association between DNA methylation and aging has been studied for decades. Thirty-five years ago, Wilson and Jones (1983) observed a marked decrease in $5 \mathrm{mC}$ content in aged normal diploid fibroblasts of mice, hamsters, and humans. Since then, age-dependent genome-wide DNA hypomethylation especially on interspersed repetitive sequence (IRS) has been detected in a variety of cell types from different tissues and organs (e.g., blood, brain) (Vanyushin et al., 1973; Bollati et al., 2009; Jintaridth and Mutirangura, 2010). Over the human lifetime, the content of $5 \mathrm{mC}$ is highest in embryos and decreases gradually as individuals age (Goel et al., 2017). In addition, region/sitespecific hypermethylation is also broadly observed in the genome during aging. For example, Rakyan et al. (2010) revealed that hypermethylated regions in human aging are preferentially located on bivalent chromatin domains and Oakes et al. (2003) showed that ribosomal DNA in the genome exhibits increased methylation in aged rats. For the time being, evidence has shown that the global reduced methylation content can be caused by down-regulated expression of Dnmts or insufficient supply of folic acid in elderly subjects (Figure 1) (Rampersaud et al., 2000; Ciccarone et al., 2016). Other works revealed that the risk factors like UV-B light, air pollution, and smoke facilitate the global hypomethylation (Prins et al., 2013; Puttipanyalears et al., 2013; Wu et al., 2013). In addition, Fernández et al. (2015) revealed that the hypomethylated sites preferentially occurs at H3K4me1-rich regions. However, the studies on the mechanism of site-specific hypermethylation currently remain very limited. Nevertheless, one hypothesis indicates that Dnmts can target specific genomic sequences based on a RNA interference mechanism (Morris et al., 2004). Moreover, there is report that the genomic regions bound by the Polycomb complex tend to be hypermethylated during aging (Jung and Pfeifer, 2015).

The crucial function of DNA methylation in multiple key processes has driven researchers to focus on the contribution of dynamic methylation changes to age-related diseases. In accordance with age-dependent hypomethylation, several age-related diseases, including neurodegenerative disease, cardiovascular disease, and cancer, show close association with marked global methylation decrease (Ehrlich, 2009; Baccarelli et al., 2010; Chouliaras et al., 2013). In addition, the examination of abnormal methylation events in certain genes provides direct evidence to strengthen the close relationship between DNA methylation and disease expression. For instance, Ozaki et al. (2017) revealed that the loss of methylation in three CpG loci in intron 1 of TREM2, an Alzheimer's disease susceptibility gene, results in higher expression of TREM2 in the leukocytes of Alzheimer's disease subjects. Ling et al. (2008) showed that PPARGC1A, a gene with effects on insulin secretion, exhibits significantly lower expression in islets from patients with type 2 diabetes and the down-regulation of PPARGC1A mRNA is caused by the increase in methylation of its promoter.

In addition, dynamic epigenetic changes during lifetimes serve as an important mechanism for organisms to adapt the
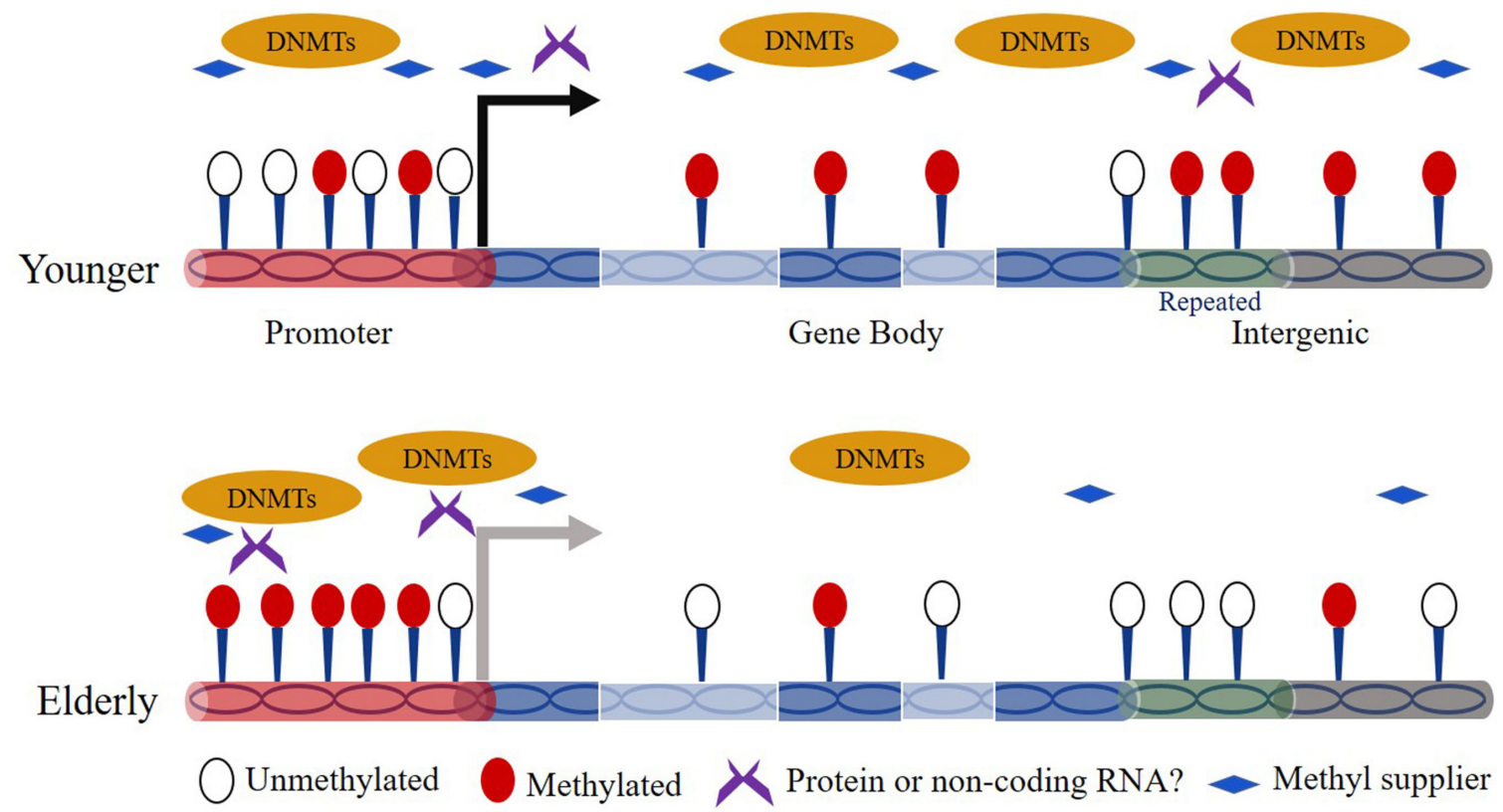

FIGURE 1 | Overview of mechanisms of dynamic DNA methylation during aging. 
external and internal environmental changes (D'Aquila et al., 2013; Schrey et al., 2016). Therefore, some dynamic methylation events during aging likely function as beneficial adaptive changes to response the stress exposure throughout the life-course. For instance, there is case that individuals can retain a high level of glucose across the famine period through methylationbased inhibition of IGF2 expression (Heijmans et al., 2008). Nevertheless, further studies are required to determine the age-related $\mathrm{CpG}$ sites with beneficial effects that are common across individuals.

\section{DNA METHYLATION-BASED AGE PREDICTION}

Growing evidence has demonstrated the successful utilization of epigenetic biomarkers in predicting age with high accuracy ( $\mathrm{Li}$ et al., 2013; Goel et al., 2017). Researchers have recently developed multiple age-prediction models with various statistical methods to determine the age of a person based on the age-dependent methylation changes in certain CpG loci (Bocklandt et al., 2011; Hannum et al., 2013; Horvath, 2013; Weidner et al., 2014). The number of $\mathrm{CpG}$ sites used in building these age predication models ranges from several to 100s. Effort has also been expended to increase the practicability of age predictors and the use of as few loci as possible. For example, Bocklandt et al. (2011) built an age-prediction model using just two $\mathrm{CpG}$ sites with a linear relationship between methylation and age in the saliva of twins and obtained an average accuracy of 5.2 years. Weidner et al. (2014) developed an age-prediction model with three CpG sites that showed age-dependent methylation changes in human blood cells, with an accuracy of less than 5 years. Others have focused on improving the stability and accuracy of the tools and utilized many $\mathrm{CpG}$ sites. Two well-known age predictors (epigenetic clocks) include Hannum's clock and Horvath's clock, which contain 71 and $353 \mathrm{CpG}$ sites, respectively (Hannum et al., 2013; Horvath, 2013), and show enhanced accuracy of 3-4 years. Notably, Hannum's clock is uniquely suitable for human blood, whereas Horvath's clock is appropriate for multiple human tissues and cells.

\section{DNA METHYLATION AGE ACCELERATION PREDICTS THE RISK OF AGE-RELATED DISORDERS}

Initially, the practicability of DNA methylation-based age predictors was considered useful in the field of forensic genetics (Yi et al., 2015). However, researchers have now proposed that DNA methylation age can also reflect the biological age, not just the chronological age, of a person (Weidner et al., 2014; Chen et al., 2016; Zhang et al., 2017a). The concept of biological age is to explain the variation in the biological status of individuals with the same chronological age (Andrews et al., 2017). Indeed, there is increasing evidence that the difference between biological age (i.e., DNA methylation age) and chronological age, often symbolized as $\Delta$ age (DNA methylation age - chronological age), is closely associated with age-related disorders. Several research groups have observed an acceleration in DNA methylation age in some age-associated diseases, including Alzheimer's disease, cardiovascular disease, and cancer (Perna et al., 2016; McCartney et al., 2018). Other cases also support the association of DNA methylation age acceleration in the expression of certain disorders. For instance, Davis et al. (2017) observed a correlation between accelerated DNA methylation age and elevated diurnal cortisol production,

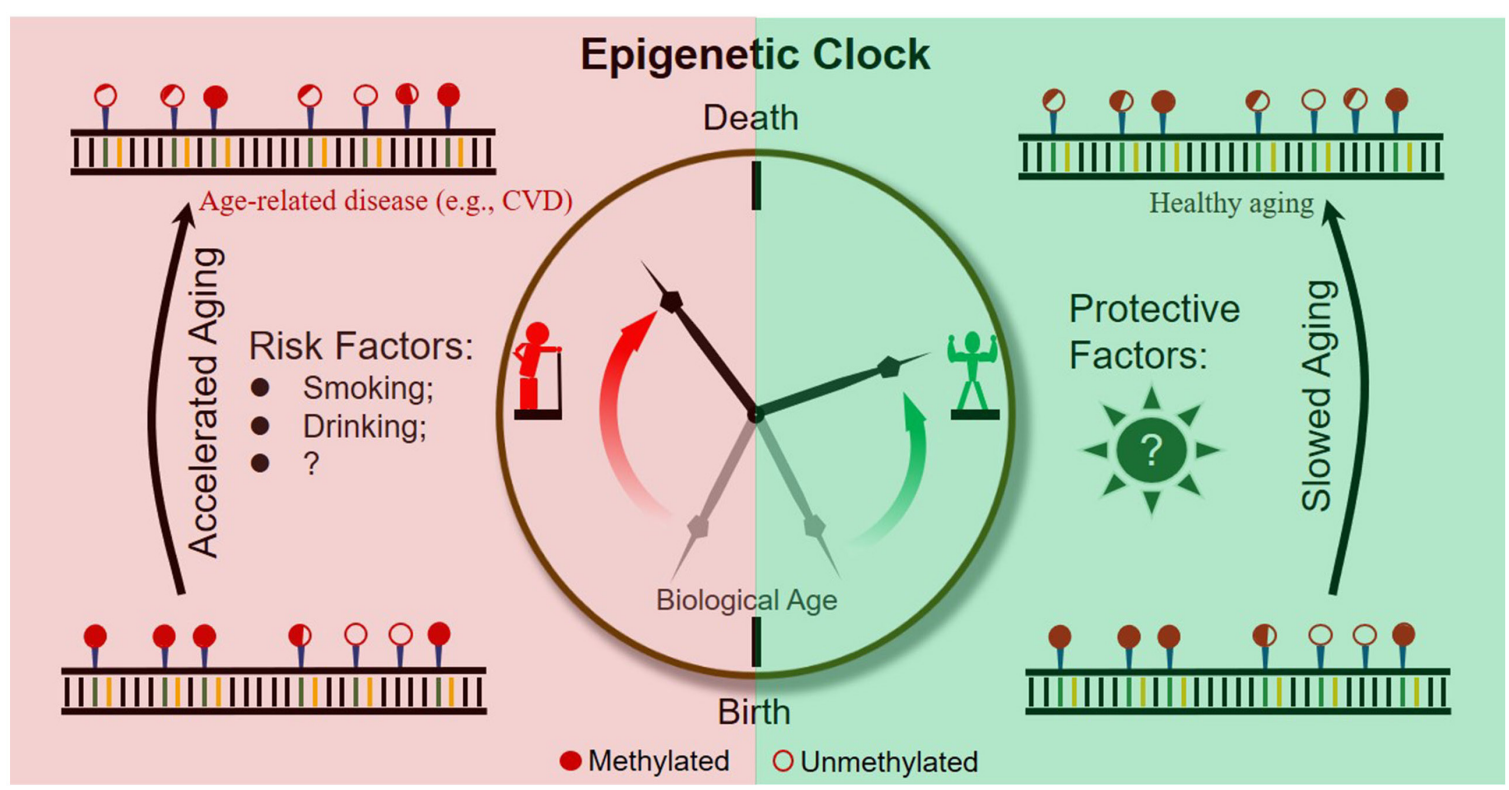

FIGURE 2 | Schematic diagram of an epigenetic clock across a human lifetime. 
which is closely linked with a reduction in hippocampal volume. Marioni et al. (2015b) showed that greater DNA methylation acceleration is correlated with lower cognitive score, weaker grip strength, and poorer lung function in humans during later life. Horvath et al. (2015a) found accelerated DNA methylation age in Down syndrome patients with clinical signatures of "accelerated aging." There is also evidence that frailty, a syndrome with a pronounced association with age-related phenotypes, has a significant association with DNA methylation age but not with telomere length (Breitling et al., 2016). Moreover, amounting evidence has shown that the $\Delta$ age is able to predict the mortality in the later life (Marioni et al., 2015a; Zheng et al., 2016). For example, Marioni et al. (2015a) revealed that a 5-year higher Hannum and Horvath $\Delta$ age are associated with a 21 and $11 \%$ of greater mortality, respectively. Zheng et al. (2016) pointed out that DNA methylation age estimated from blood tissue can also be used to predict cancer incidence and mortality. However, another study of Zhang et al. (2017b) analyzed the CpG sites that are specific to the indicative of disease-related outcomes and mortality and showed a big difference with those in tracking natural aging. Accordingly, we suppose that it is necessary to develop directed prediction models for various age-related outcomes through integrating the age-related and disease-specific CpG sites.

The intrinsic and extrinsic factors contributing to the acceleration of epigenetic age have also attracted attention. One broadly focused risk factor is cumulative lifetime stress, with its contribution to accelerated DNA methylation age revealed in many studies (Zannas et al., 2015; Wolf et al., 2016, 2018a,b). In addition, the finding that certain CpG loci affected by drinking and smoking present the same methylation changes as aging suggests the potential roles of these activities in accelerating DNA methylation age (Xiao et al., 2018). Other factors include age at menopause, which is closely associated with epigenetic age acceleration in women (Levine et al., 2016). A correlation between obesity and accelerated epigenetic aging has also been observed in middle-aged individuals (Nevalainen et al., 2017).

\section{RELATIONSHIP BETWEEN DNA METHYLATION AGE AND LONGEVITY}

Longevity, which is a trait of extreme aging, is also associated with age-related DNA methylation changes (Gravina and Vijg, 2010; Jones et al., 2015; Xiao et al., 2016). A growing body of research has investigated the methylation signatures of longlived people (e.g., centenarians) (Heyn et al., 2012; Gentilini et al., 2013; Xiao et al., 2015), who exhibit a delayed age of onset for some age-associated diseases (Hitt et al., 1999; Engberg et al., 2009; Andersen et al., 2012). Previous studies indicate that the specific methylation profiles of long-lived people have potential roles in suppressing the occurrence of age-related diseases (Xiao et al., 2015). In addition, research has shown that semi-supercentenarians and their offspring have a relatively younger biological age as reflected by their decreased DNA methylation age (Horvath et al., 2015b). What's more, Lin et al. (2016) suggested that DNA methylation level of several CpG sites (e.g., associated with $P D E 4 C$ and CLCN6) likely has an association with life-expectancy. Interestingly, there are emerging reports that the epigenetic clocks tick faster in mice than those in humans, indicating a potential association between epigenetic clocks and the maximum life-span of mammals (Stubbs et al., 2017; Wagner, 2017; Lowe et al., 2018).

\section{CONCLUSION AND PERSPECTIVES}

It is becoming evident that epigenetic clocks based on the dynamic methylation of certain CpG loci during aging are of help in the prediction of chronological and biological age (Figure 2). In addition, abundant research indicates that the ticking rate of an epigenetic clock is associated with age-related diseases and longevity. Taken together, evidence obtained so far suggests the great potential of dynamic methylation as a "prophet" of agerelated outcomes, including the pathology and health status of a person.

However, to further expand the practical application of epigenetic clocks, researchers should make efforts to address the following two important issues. First, as current epigenetic clocks are only correlated with age-related outcomes, the development of specific epigenetic clocks by combining outcome-specific $\mathrm{CpG}$ sites is necessary. Second, to slow down the rate of epigenetic aging throughout the lifetime of humans, risk factors accelerating epigenetic clocks and protective factors slowing epigenetic clocks should be identified and extensively studied (Figure 2).

\section{ETHICS STATEMENT}

The research protocol was approved by the Ethics Committee at Kunming Institute of Zoology, Chinese Academy of Sciences.

\section{AUTHOR CONTRIBUTIONS}

Q-PK and F-HX conceived the project and wrote the manuscript. $\mathrm{H}-\mathrm{TW}$ revised the manuscript.

\section{FUNDING}

This work was supported by grants from National Key R\&D Program of China (Grant No. SQ2018YFC200162), National Natural Science Foundation of China (Grant Nos. 91749109 and 81701394), Key Research Program of Frontier Sciences of the Chinese Academy of Sciences (Grant No. QYZDBSSW-SMC020), Yunnan Applied Basic Research Project (Grant No. 2018FB121), Youth Innovation Promotion Association of the Chinese Academy of Sciences (to Q-PK), and West Light Foundation of the Chinese Academy of Sciences (to F-HX).

\section{ACKNOWLEDGMENTS}

We would like to appreciate Dr. Christine Watts for her help in honing the manuscript. 


\section{REFERENCES}

Andersen, S. L., Sebastiani, P., Dworkis, D. A., Feldman, L., and Perls, T. T. (2012). Health span approximates life span among many supercentenarians: compression of morbidity at the approximate limit of life span. J. Gerontol. A Biol. Sci. Med. Sci. 67, 395-405. doi: 10.1093/gerona/glr223

Andrews, C., Nettle, D., Larriva, M., Gillespie, R., Reichert, S., Brilot, B. O., et al. (2017). A marker of biological age explains individual variation in the strength of the adult stress response. R. Soc. Open Sci. 4:171208. doi: 10.1098/rsos.171208

Andrews, S. V., Sheppard, B., Windham, G. C., Schieve, L. A., Schendel, D. E., Croen, L. A., et al. (2018). Case-control meta-analysis of blood DNA methylation and autism spectrum disorder. Mol. Autism 9:40. doi: 10.1186/ s13229-018-0224-6

Baccarelli, A., Wright, R. O., Bollati, V., Litonjua, A. A., Zanobetti, A., Tarantini, L., et al. (2010). Ischemic heart disease and stroke in relation to blood DNA methylation. Epidemiology 21, 819-828. doi: 10.1097/EDE.0b013e3181f20457

Bird, A. J. N. (1986). CpG-rich islands and the function of DNA methylation. Nature 321, 209-213. doi: 10.1038/321209a0

Bocklandt, S., Lin, W., Sehl, M. E., Sanchez, F. J., Sinsheimer, J. S., Horvath, S., et al. (2011). Epigenetic predictor of age. PLoS One 6:e14821. doi: 10.1371/journal. pone.0014821

Bollati, V., Schwartz, J., Wright, R. O., Litonjua, A. A., Tarantini, L., Suh, H. H., et al. (2009). Decline in genomic DNA methylation through aging in a cohort of elderly subjects. Mech. Ageing Dev. 130, 234-239. doi: 10.1016/j.mad.2008. 12.003

Breitling, L. P., Saum, K. U., Perna, L., Schottker, B., Holleczek, B., and Brenner, H. (2016). Frailty is associated with the epigenetic clock but not with telomere length in a German cohort. Clin. Epigenetics 8:21. doi: 10.1186/s13148-0160186-5

Chao, M. P., Seita, J., and Weissman, I. L. (2008). Establishment of a normal hematopoietic and leukemia stem cell hierarchy. Cold Spring Harb. Symp. Quant. Biol. 73, 439-449. doi: 10.1101/sqb.2008.73.031

Chen, B. H., Marioni, R. E., Colicino, E., Peters, M. J., Ward-Caviness, C. K., Tsai, P. C., et al. (2016). DNA methylation-based measures of biological age: metaanalysis predicting time to death. Aging 8, 1844-1865. doi: 10.18632/aging. 101020

Chen, Z. X., and Riggs, A. D. (2011). DNA methylation and demethylation in mammals. J. Biol. Chem. 286, 18347-18353. doi: 10.1074/jbc.R110.205286

Chiang, P. K., Gordon, R. K., Tal, J., Zeng, G. C., Doctor, B. P., Pardhasaradhi, K., et al. (1996). S-Adenosylmethionine and methylation. FASEB J. 10, 471-480. doi: 10.1096/fasebj.10.4.8647346

Chouliaras, L., Mastroeni, D., Delvaux, E., Grover, A., Kenis, G., Hof, P. R., et al. (2013). Consistent decrease in global DNA methylation and hydroxymethylation in the hippocampus of Alzheimer's disease patients. Neurobiol. Aging 34, 2091-2099. doi: 10.1016/j.neurobiolaging.2013.02.021

Christensen, K., Doblhammer, G., Rau, R., and Vaupel, J. W. (2009). Ageing populations: the challenges ahead. Lancet 374, 1196-1208. doi: 10.1016/S01406736(09)61460-4

Ciccarone, F., Malavolta, M., Calabrese, R., Guastafierro, T., Bacalini, M. G., Reale, A., et al. (2016). Age-dependent expression of DNMT1 and DNMT3B in PBMCs from a large European population enrolled in the MARK-AGE study. Aging Cell 15, 755-765. doi: 10.1111/acel.12485

Comb, M., and Goodman, H. M. (1990). CpG methylation inhibits proenkephalin gene expression and binding of the transcription factor AP-2. Nucleic Acids Res. 18, 3975-3982. doi: 10.1093/nar/18.13.3975

Côté, S., Gagné-Ouellet, V., Guay, S. P., Allard, C., Houde, A. A., Perron, P., et al. (2016). PPARGC1 $\alpha$ gene DNA methylation variations in human placenta mediate the link between maternal hyperglycemia and leptin levels in newborns. Clin. Epigenetics 8:72. doi: 10.1186/s13148-016-0239-9

D’Aquila, P., Rose, G., Bellizzi, D., and Passarino, G. (2013). Epigenetics and aging. Maturitas 74, 130-136. doi: 10.1016/j.maturitas.2012.11.005

Davis, E. G., Humphreys, K. L., McEwen, L. M., Sacchet, M. D., Camacho, M. C., MacIsaac, J. L., et al. (2017). Accelerated DNA methylation age in adolescent girls: associations with elevated diurnal cortisol and reduced hippocampal volume. Transl. Psychiatry 7:e1223. doi: 10.1038/tp.2017.188

Dugué, P. A., Bassett, J. K., Joo, J. E., Baglietto, L., Jung, C. H., Wong, E. M., et al. (2018). Association of DNA methylation-based biological age with health riskk factors and overall and cause-specific mortality. Am. J. Epidemiol. 187, 529-538. doi: 10.1093/aje/kwx291

Eden, S., and Cedar, H. J. (1994). Role of DNA methylation in the regulation of transcription. Curr. Opin. Genet. Dev. 4, 255-259. doi: 10.1016/S0959-437X(05) 80052-8

Ehrlich, M., Gama-Sosa, M. A., Huang, L. H., Midgett, R. M., Kuo, K. C., McCune, R. A., et al. (1982). Amount and distribution of 5-methylcytosine in human DNA from different types of tissues of cells. Nucleic Acids Res. 10, 2709-2721. doi: 10.1093/nar/10.8.2709

Ehrlich, M. J. E. (2009). DNA hypomethylation in cancer cells. Epigenomics 1, 239-259. doi: 10.2217/epi.09.33

Engberg, H., Oksuzyan, A., Jeune, B., Vaupel, J. W., and Christensen, K. (2009). Centenarians-a useful model for healthy aging? A 29-year follow-up of hospitalizations among 40,000 Danes born in 1905. Aging Cell 8, 270-276. doi: 10.1111/j.1474-9726.2009.00474.x

Farlik, M., Halbritter, F., Muller, F., Choudry, F. A., Ebert, P., Klughammer, J., et al. (2016). DNA methylation dynamics of human hematopoietic stem cell differentiation. Cell Stem Cell 19, 808-822. doi: 10.1016/j.stem.2016.10.019

Feinberg, A. P., Oshimura, M., and Barrett, J. C. (2002). Epigenetic mechanisms in human disease. Cancer Res. 62, 6784-6787.

Fernández, A. F., Bayón, G. F., Urdinguio, R. G., Toraño, E. G., García, M. G., Carella, A., et al. (2015). H3K4mel marks DNA regions hypomethylated during aging in human stem and differentiated cells. Genome Res. 25, 27-40. doi: $10.1101 /$ gr.169011.113

Fraga, M. F., and Esteller, M. (2007). Epigenetics and aging: the targets and the marks. Trends Genet. 23, 413-418. doi: 10.1016/j.tig.2007.05.008

Fuks, F., Hurd, P. J., Wolf, D., Nan, X., Bird, A., and Kouzarides, T. (2003). The methyl-CpG-binding protein MeCP2 links DNA methylation to histone methylation. J. Biol. Chem. 278, 4035-4040. doi: 10.1074/jbc.M2102 56200

Gentilini, D., Mari, D., Castaldi, D., Remondini, D., Ogliari, G., Ostan, R., et al. (2013). Role of epigenetics in human aging and longevity: genome-wide DNA methylation profile in centenarians and centenarians' offspring. Age 35, 1961-1973. doi: 10.1007/s11357-012-9463-1

Goel, N., Karir, P., and Garg, V. K. (2017). Role of DNA methylation in human age prediction. Mech. Ageing Dev. 166, 33-41. doi: 10.1016/j.mad.2017.08.012

Gravina, S., and Vijg, J. (2010). Epigenetic factors in aging and longevity. Pflugers Arch. 459, 247-258. doi: 10.1007/s00424-009-0730-7

Hannum, G., Guinney, J., Zhao, L., Zhang, L., Hughes, G., Sadda, S., et al. (2013). Genome-wide methylation profiles reveal quantitative views of human aging rates. Mol. Cell 49, 359-367. doi: 10.1016/j.molcel.2012.10.016

Heijmans, B. T., Tobi, E. W., Stein, A. D., Putter, H., Blauw, G. J., Susser, E. S., et al. (2008). Persistent epigenetic differences associated with prenatal exposure to famine in humans. Proc. Natl. Acad. Sci. U.S.A. 105, 17046-17049. doi: $10.1073 /$ pnas. 0806560105

Hendrich, B., Hardeland, U., Ng, H. H., Jiricny, J., and Bird, A. (1999). The thymine glycosylase MBD4 can bind to the product of deamination at methylated $\mathrm{CpG}$ sites. Nature 401, 301-304. doi: 10.1038/45843

Herman, J. G., and Baylin, S. B. (2003). Gene silencing in cancer in association with promoter hypermethylation. N. Engl. J. Med. 349, 2042-2054. doi: 10.1056/ NEJMra023075

Heyn, H., Li, N., Ferreira, H. J., Moran, S., Pisano, D. G., Gomez, A., et al. (2012). Distinct DNA methylomes of newborns and centenarians. Proc. Natl. Acad. Sci. U.S.A. 109, 10522-10527. doi: 10.1073/pnas.1120658109

Hitt, R., Young-Xu, Y., Silver, M., and Perls, T. (1999). Centenarians: the older you get, the healthier you have been. Lancet 354, 652-652. doi: 10.1016/S01406736(99)01987-X

Horvath, S. (2013). DNA methylation age of human tissues and cell types. Genome Biol. 14:R115. doi: 10.1186/gb-2013-14-10-r115

Horvath, S., Garagnani, P., Bacalini, M. G., Pirazzini, C., Salvioli, S., Gentilini, D., et al. (2015a). Accelerated epigenetic aging in down syndrome. Aging Cell 14, 491-495. doi: 10.1111/acel.12325

Horvath, S., Pirazzini, C., Bacalini, M. G., Gentilini, D., Di Blasio, A. M., Delledonne, M., et al. (2015b). Decreased epigenetic age of PBMCs from Italian semi-supercentenarians and their offspring. Aging 7, 1159-1170.

Hotchkiss, R. (1948). The quantitative separation of purines, pyrimidines, and nucleosides by paper chromatography. J. Biol. Chem. 175, 315-332. 
Ichiyama, K., Chen, T., Wang, X., Yan, X., Kim, B. S., Tanaka, S., et al. (2015). The methylcytosine dioxygenase Tet2 promotes DNA demethylation and activation of cytokine gene expression in T cells. Immunity 42, 613-626. doi: 10.1016/j. immuni.2015.03.005

Jin, C., Lu, Y., Jelinek, J., Liang, S., Estecio, M. R. H., Barton, M. C., et al. (2014). TET1 is a maintenance DNA demethylase that prevents methylation spreading in differentiated cells. Nucleic Acids Res. 42, 6956-6971. doi: 10.1093/ nar/gku372

Jintaridth, P., and Mutirangura, A. (2010). Distinctive patterns of age-dependent hypomethylation in interspersed repetitive sequences. Physiol. Genomics 41, 194-200. doi: 10.1152/physiolgenomics.00146.2009

Jones, M. J., Goodman, S. J., and Kobor, M. S. (2015). DNA methylation and healthy human aging. Aging Cell 14, 924-932. doi: 10.1111/acel.12349

Jones, P. L., Veenstra, G. J., Wade, P. A., Vermaak, D., Kass, S. U., Landsberger, N., et al. (1998). Methylated DNA and MeCP2 recruit histone deacetylase to repress transcription. Nature 19, 187-191.

Jost, J. P., Schwarz, S., Hess, D., Angliker, H., Fuller-Pace, F. V., Stahl, H., et al. (1999). A chicken embryo protein related to the mammalian DEAD box protein p68 is tightly associated with the highly purified protein-RNA complex of 5MeC-DNA glycosylase. Nucleic Acids Res. 27, 3245-3252. doi: 10.1093/nar/27. 16.3245

Jung, M., and Pfeifer, G. P. (2015). Aging and DNA methylation. BMC Biol. 13:7. doi: 10.1186/s12915-015-0118-4

Kennedy, B. K., Berger, S. L., Brunet, A., Campisi, J., Cuervo, A. M., Epel, E. S., et al. (2014). Geroscience: linking aging to chronic disease. Cell 159, 709-713. doi: 10.1016/j.cell.2014.10.039

Levine, M. E., Lu, A. T., Chen, B. H., Hernandez, D., Singleton, A. B., Ferrucci, L., et al. (2016). Menopause accelerates biological aging. Proc. Natl. Acad. Sci. U.S.A. 113, 9327-9332. doi: 10.1073/pnas.1604558113

Li, M., Liu, W., Yuan, T., Bai, R., Liu, G. H., Zhang, W., et al. (2013). DNA methylome: unveiling your biological age. Protein Cell 4, 723-725. doi: 10.1007/ s13238-013-3913-0

Lin, Q., Weidner, C. I., Costa, I. G., Marioni, R. E., Ferreira, M. R. P., Deary, I. J., et al. (2016). DNA methylatation levels at individual age-associated CpG sites can be indicative for life expectancy. Aging 8, 394-401. doi: 10.18632/aging. 100908

Ling, C., Guerra, S. D., Lupi, R., Ronn, T., Granhall, C., Luthman, H., et al. (2008). Epigenetic regulation of PPARGC1A in human type 2 diabetic islets and effect on insulin secretion. Diabetologia 51, 615-622. doi: 10.1007/s00125-007-0916-5

Lister, R., Pelizzola, M., Dowen, R. H., Hawkins, R. D., Hon, G., Tonti-Filippini, J., et al. (2009). Human DNA methylomes at base resolution show widespread epigenomic differences. Nature 462, 315-322. doi: 10.1038/nature08514

Lopezotin, C., Blasco, M. A., Partridge, L., Serrano, M., and Kroemer, G. J. C. (2013). The hallmarks of aging. Cell 153, 1194-1217. doi: 10.1016/j.cell.2013. 05.039

Lowe, R., Barton, C., Jenkins, C. A., Ernst, C., Forman, O., Fernandez-Twinn, D. S., et al. (2018). Ageing-associated DNA methylation dynamics are a molecular readout of lifespan variation among mammalian species. Genome Biol. 19:22. doi: 10.1186/s13059-018-1397-1

Lutz, W., Sanderson, W., and Scherbov, S. J. N. (2008). The coming acceleration of global population ageing. Nature 451, 716-719. doi: 10.1038/nature06516

Marioni, R. E., Harris, S. E., Shah, S., McRae, A. F., von Zglinicki, T., Martin-Ruiz, C., et al. (2016). The epigenetic clock and telomere length are independently associated with chronological age and mortality. Int. J. Epidemiol. 45, 424-432. doi: 10.1093/ije/dyw041

Marioni, R. E., Shah, S., McRae, A. F., Chen, B. H., Colicino, E., Harris, S. E., et al. (2015a). DNA methylation age of blood predicts all-cause mortality in later life. Genome Biol. 16:25. doi: 10.1186/s13059-015-0584-6

Marioni, R. E., Shah, S., Mcrae, A. F., Ritchie, S. J., Muniz-Terrera, G., Harris, S. E., et al. (2015b). The epigenetic clock is correlated with physical and cognitive fitness in the Lothian Birth Cohort 1936. Int. J. Epidemiol. 44, 1388-1396. doi: 10.1093/ije/dyu277

Maunakea, A. K., Nagarajan, R. P., Bilenky, M., Ballinger, T. J., D’Souza, C., Fouse, S. D., et al. (2010). Conserved role of intragenic DNA methylation in regulating alternative promoters. Nature 466, 253-257. doi: 10.1038/nature09165

McCartney, D. L., Stevenson, A. J., Walker, R. M., Gibson, J., Morris, S. W., Campbell, A., et al. (2018). Investigating the relationship between
DNA methylation age acceleration and risk factors for Alzheimer's disease. Alzheimers Dement. 10, 429-437. doi: 10.1016/j.dadm.2018.05.006

Moore, L. D., Le, T., and Fan, G. J. N. (2013). DNA methylation and its basic function. Neuropsychopharmacology 38, 23-38. doi: 10.1038/npp.2012.112

Morris, K. V., Chan, S. W. L., Jacobsen, S. E., and Looney, D. J. (2004). Small interfering RNA-induced transcriptional gene silencing in human cell. Science 305, 1289-1292. doi: 10.1126/science.1101372

Müezzinler, A., Zaineddin, A. K., and Brenner, H. (2013). A systematic review of leukocyte telomere length and age in adults. Ageing Res. Rev. 12, 509-519. doi: 10.1016/j.arr.2013.01.003

Neri, F., Rapelli, S., Krepelova, A., Incarnato, D., Parlato, C., Basile, G., et al. (2017). Intragenic DNA methylation prevents spurious transcription initiation. Nature 543, 72-77. doi: 10.1038/nature21373

Nevalainen, T., Kananen, L., Marttila, S., Jylhava, J., Mononen, N., Kahonen, M., et al. (2017). Obesity accelerates epigenetic aging in middle-aged but not in elderly individuals. Clin. Epigenetics 9:20. doi: 10.1186/s13148-016-0 301-7

Nichols, M., Townsend, N., Scarborough, P., and Rayner, M. (2014). Cardiovascular disease in Europe 2014: epidemiological update. Eur. Heart J. 35, 2950-2959. doi: 10.1093/eurheartj/ehu299

Oakes, C. C., Smiraglia, D. J., Plass, C., Trasler, J. M., and Robaire, B. (2003). Aging results in hypermethylation of ribosomal DNA in sperm and liver of male rats. Proc. Natl. Acad. Sci. U.S.A. 100, 1775-1780. doi: 10.1073/pnas.04379 71100

Okano, M., Bell, D. W., Haber, D. A., and Li, E. J. C. (1999). DNA methyltransferases Dnmt3a and Dnmt3b are essential for de novo methylation and mammalian development. Cell 99, 247-257. doi: 10.1016/S0092-8674(00) 81656-6

Ozaki, Y., Yoshino, Y., Yamazaki, K., Sao, T., Mori, Y., Ochi, S., et al. (2017). DNA methylation changes at TREM2 intron 1 and TREM2 mRNA expression in patients with Alzheimer's disease. J. Psychiatr. Res. 92, 74-80. doi: 10.1016/j. jpsychires.2017.04.003

Pagidipati, N. J., and Gaziano, T. A. J. C. (2013). Estimating deaths from cardiovascular disease: a review of global methodologies of mortality measurement. Circulation 127, 749-756. doi: 10.1161/CIRCULATIONAHA. 112.128413

Perna, L., Zhang, Y., Mons, U., Holleczek, B., Saum, K. U., and Brenner, H. (2016). Epigenetic age acceleration predicts cancer, cardiovascular, and all-cause mortality in a German case cohort. Clin. Epigenetics 8:64. doi: 10.1186/s13148016-0228-z

Prins, S. D., Koppen, G., Jacobs, G., Dons, E., Mieroop, E. V. D., Nelen, V., et al. (2013). Influence of ambient air pollution on global DNA methylation in healthy adults: a seasonal follow-up. Environ. Int. 59, 418-424. doi: 10.1016/j. envint.2013.07.007

Puttipanyalears, C., Subbalekha, K., Kitkumthorn, N., and Mutriangura, A. (2013). Alu hypomethylation in smoke-exposed epithelia and oral squamous carcinoma. Asian Pac. J. Cancer Prev. 14, 5495-5501. doi: 10.7314/APJCP.2013. 14.9.5495

Rakyan, V. K., Down, T. A., Maslau, S., Andrew, T., Yang, T., Beyan, H., et al. (2010). Human aging-associated DNA hypermethylation occurs preferentially at bivalent chromatin domains. Genome Res. 20, 434-439. doi: 10.1101/gr. 103101.109

Rampersaud, G. C., Kauwell, G. P. A., Hutson, A. D., Cerda, J. J., and Bailey, L. B. (2000). Genomic DNA methylation decreases in response to moderate folate depletion in elderly women. Am. J. Clin. Nutr. 72, 998-1003. doi: 10.1093/ajcn/ 72.4 .998

Richardson, B. (2003a). DNA methylation and autoimmune disease. Clin. Immunol. 109, 72-79.

Richardson, B. (2003b). Impact of aging on DNA methylation. Ageing Res. Rev. 2, 245-261.

Rizvi, S., Raza, S. T., and Mahdi, F. J. C. A. S. (2015). Telomere length variations in aging and age-related diseases. Curr. Aging Sci. 7, 161-167. doi: 10.2174/ 1874609808666150122153151

Robertson, K. D. (2005). DNA methylation and human disease. Nat. Rev. Genet. 6, 597-610. doi: 10.1038/nrg1655

Sato, N., Fukushima, N., Matsubayashi, H., and Goggins, M. J. O. (2004). Identification of maspin and S100P as novel hypomethylation targets in 
pancreatic cancer using global gene expression profiling. Oncogene 23, 15311538. doi: 10.1038/sj.onc. 1207269

Schrey, A. W., Robbins, T. R., Lee, J., Dukes, D. W., Ragsdale, A. K., Thawley, C. J., et al. (2016). Epigenetic response to environmental change: DNA methylation varies with invasion status. Environ. Epigenet. 2:dvw008. doi: 10.1093/eep/ dvw008

Sen, P., Shah, P. P., Nativio, R., and Berger, S. L. (2016). Epigenetic mechanisms of longevity and aging. Cell 166, 822-839. doi: 10.1016/j.cell.2016.07.050

Stubbs, T. M., Bonder, M. J., Stark, A. K., Krueger, F., Bi, Ageing Clock Team, von, Meyenn F, et al. (2017). Multi-tissue DNA methylation age predictor in mouse. Genome Biol. 18:68. doi: 10.1186/s13059-017-1203-5

Trowbridge, J. J., Snow, J. W., Kim, J., and Orkin, S. H. (2009). DNA methyltransferase 1 is essential for and uniquely regulates hematopoietic stem and progenitor cells. Cell Stem Cell 5, 442-449. doi: 10.1016/j.stem.2009.08.016

Vaiserman, A. M. (2018). Developmental tuning of epigenetic clock. Front. Genet. 9:584. doi: 10.3389/fgene.2018.00584

Vanyushin, B. F., Nemirovsky, L. E., Klimenko, V. V., Vasiliev, V. K., and Belozersky, A. N. (1973). The 5-methylcytosine in DNA of rats. Gerontology 19, 138-152. doi: 10.1159/000211967

Vilkaitis, G., Suetake, I., Klimasauskas, S., and Tajima, S. J. (2005). Processive methylation of hemimethylated $\mathrm{CpG}$ sites by mouse Dnmt1 DNA methyltransferase. J. Biol. Chem. 280, 64-72. doi: 10.1074/jbc.M411126200

Wagner, W. (2017). Epigenetic aging clocks in mice and men. Genome Biol. 18:107. doi: 10.1186/s13059-017-1245-8

Weidner, C. I., Lin, Q., Koch, C. M., Eisele, L., Beier, F., Ziegler, P., et al. (2014). Aging of blood can be tracked by DNA methylation changes at just three CpG sites. Genome Biol. 15:R24. doi: 10.1186/gb-2014-15-2-r24

Wilson, V. L., and Jones, P. A. (1983). DNA methylation decreases in aging but not in immortal cells. Science 220, 1055-1057. doi: 10.1126/science.6844925

Wolf, E. J., Logue, M. W., Hayes, J. P., Sadeh, N., Schichman, S. A., Stone, A., et al. (2016). Accelerated DNA methylation age: associations with PTSD and neural integrity. Psychoneuroendocrinology 63, 155-162. doi: 10.1016/j.psyneuen.2015. 09.020

Wolf, E. J., Logue, M. W., Stoop, T. B., Schichman, S. A., Stone, A., Sadeh, N., et al. (2018a). Accelerated DNA methylation age: associations with posttraumatic stress disorder and mortality. Psychosom. Med. 80, 42-48. doi: 10.1097/PSY. 0000000000000506

Wolf, E. J., Maniates, H., Nugent, N., Maihofer, A. X., Armstrong, D., Ratanatharathorn, A., et al. (2018b). Traumatic stress and accelerated DNA methylation age: a meta-analysis. Psychoneuroendocrinology 92, 123-134. doi: 10.1016/j.psyneuen.2017.12.007

Wolffe, A. P., Jones, P. L., and Wade, P. A. (1999). DNA demethylation. Proc. Natl. Acad. Sci. U.S.A. 96, 5894-5896. doi: 10.1073/pnas.96.11.5894

Wu, Z., Li, X., Qin, H., Zhu, X., Xu, J., and Shi, W. (2013). Ultraviolet B enhances DNA hypomethylation of CD4+ T cells in systemic lupus erythematosus via inhibiting DNMT1 catalytic activity. J. Dermatol. Sci. 71, 167-173. doi: 10.1016/ j.jdermsci.2013.04.022

Xiao, F. H., Chen, X. Q., He, Y. H., and Kong, Q. P. (2018). Accelerated DNA methylation changes in middle-aged men define sexual dimorphism in human lifespans. Clin. Epigenetics 10:133. doi: 10.1186/s13148-018-0573-1

Xiao, F. H., He, Y. H., Li, Q. G., Wu, H., Luo, L. H., and Kong, Q. P. (2015). A genome-wide scan reveals important roles of DNA methylation in human longevity by regulating age-related disease genes. PLoS One 10:e0120388. doi: 10.1371/journal.pone.0120388

Xiao, F. H., Kong, Q. P., Perry, B., and He, Y. H. (2016). Progress on the role of DNA methylation in aging and longevity. Brief. Funct. Genomics 15, 454-459. doi: 10.1093/bfgp/elw009

Yang, X., Han, H., Carvalho, D. D. D., Lay, F. D., Jones, P. A., and Liang, G. (2014). Gene body methylation can alter gene expression and is therapeutic target in cancer. Cancer Cell 26, 577-590. doi: 10.1016/j.ccr.2014.07.028

Yi, S. H., Jia, Y. S., Mei, K., Yang, R. Z., and Huang, D. X. (2015). Age-related DNA methylation changes for forensic age-prediction. Int. J. Legal Med. 129, 237-244. doi: 10.1007/s00414-014-1100-3

Zannas, A. S., Arloth, J., Carrillo-Roa, T., Iurato, S., Roh, S., Ressler, K. J., et al. (2015). Lifetime stress accelerates epigenetic aging in an urban, African American cohort: relevance of glucocorticoid signaling. Genome Biol. 16:266. doi: 10.1186/s13059-015-0828-5

Zhang, Y., Hapala, J., Brenner, H., and Wagner, W. (2017a). Individual CpG sites that are associated with age and life expectancy become hypomethylated upon aging. Clin. Epigenetics 9:9. doi: 10.1186/s13148-017-0315-9

Zhang, Y., Wilson, R., Heiss, J., Breitling, L. P., Saum, K. U., Schottker, B., et al. (2017b). DNA methylation signatures in peripheral blood strongly predit all-cause mortality. Nat. Commun. 8:14617. doi: 10.1038/ncomms 14617

Zheng, Y., Joyce, B. T., Colicino, E., Liu, L., Zhang, W., Dai, Q., et al. (2016). Blood epigenetic age may predict cancer incidence and mortality. EBioMedicine 5, 68-73. doi: 10.1016/j.ebiom.2016.02.008

Zhu, J. K. (2009). Active DNA methylation mediated by DNA glycosylases. Annu. Rev. Genet. 43, 143-166. doi: 10.1146/annurev-genet-102108-134205

Conflict of Interest Statement: The authors declare that the research was conducted in the absence of any commercial or financial relationships that could be construed as a potential conflict of interest.

Copyright (c) 2019 Xiao, Wang and Kong. This is an open-access article distributed under the terms of the Creative Commons Attribution License (CC BY). The use, distribution or reproduction in other forums is permitted, provided the original author(s) and the copyright owner(s) are credited and that the original publication in this journal is cited, in accordance with accepted academic practice. No use, distribution or reproduction is permitted which does not comply with these terms. 